\title{
Absorption of glucose, sodium, and water by the human jejunum studied by intestinal perfusion with a proximal occluding balloon and at variable flow
} rates

\author{
R. MODIGLIANI AND J. J. BERNIER \\ From the National Institute of Health and Medical Research, St-Lazare Hospital, Paris, France
}

SUMMARY A perfusion technique with a proximal occluding balloon has been used to study the absorption of glucose, sodium, and water from the human jejunum at different rates of flow. The absorption of glucose and water was significantly higher with the balloon deflated than inflated, probably because of reflux of infused solution above the point of infusion. Above the inflated balloon 0 to $4.2 \mathrm{ml} / \mathrm{min}$ of endogenous secretions could be recovered. Increasing flow rates increase the glucose absorption rate; a single relationship could be found between the glucose load and glucose absorption rate, and single values for the maximum velocity and for the half saturating load were calculated whatever the infusing rate and the initial glucose concentration. The stimulating effect of glucose on water and sodium movement increases gradually when the initial iugar concentration varies from 14 to $133 \mathrm{mM} / 1$. Above this concentration a drop in water and sodium movement is observed, although the initial sodium concentration is kept constant. High flow rates result in a decrease of water absorption and an increase in sodium and potassium secretion rates.

Intestinal perfusion techniques have been widely used to study the absorption of sugars, water, and electrolytes in man (Holdsworth and Dawson, 1964; Gray and Ingelfinger, 1966; Whalen, Harris, Geenen, and Soergel, 1966; McMichael, Webb, and Dawson, 1967; Fordtran, Rector, and Carter, 1968). Nevertheless a controversy still persists about the use of a double or a triple lumen tube (Sladen and Dawson, 1968; Fordtran, 1969). Moreover, although a recent paper deals with the effects of flow rates on the absorption of glucose (Sladen and Dawson, 1969b), the exact consequences of varying flow rates have not yet been reported, especially with regard to the kinetics of glucose absorption and the movement of water and electrolytes. The present study was undertaken to investigate these two problems further.

\section{Methods}

Twenty-nine subjects, aged between 25 and 65 years, were studied. They were either patients with minor Received for publication 17 September 1970. abdominal complaints or entirely normal subjects. None had any evidence of small bowel disease.

A technique utilizing a proximal occluding balloon was used (Phillips and Summerskill, 1966) to prevent contamination by endogenous secretions and reflux of the infused solution above the infusion point. Immediately above the balloon a tube allowed continuous aspiration of the gut. The infusion tube was immediately below the balloon. The test segment was $25 \mathrm{~cm}$ long and perfusate was aspirated via a third tube. There was a fourth tube to inflate the balloon (Fig. 1).

The tube was swallowed by the subject and perfusion started when the infusing point was at the duodenojejunal junction; this took between 12 and 36 hours and the position of the tube was checked fluoroscopically. The subjects fasted (no food or fluid allowed) for 12 hours before the test.

At the beginning of the infusion, the balloon was inflated with $40 \mathrm{ml}$ of air and its occluding effect was checked when bromsulphthalein introduced above the balloon was not recovered at the sampling site 


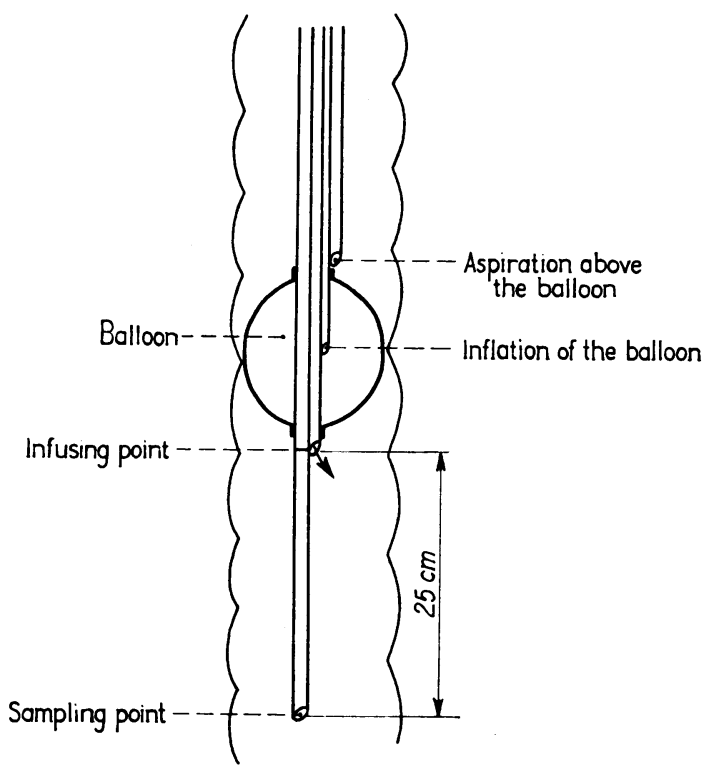

Fig. 1 Diagram of the tube with a proxima! occluding balloon.

and also the perfused glucose-containing solution above the balloon. This occluding effect was tested several times during the infusion periods. These criteria were fulfilled in all experiments.

Four rates of infusion were used in three different groups of subjects: six subjects were infused at $8 \mathrm{ml} / \mathrm{min}, 13$ subjects at $10 \mathrm{ml} / \mathrm{min}$, and 10 subjects were infused on two successive days at 15 and 20 $\mathrm{ml} / \mathrm{min}$. At the rates of 10,15 , and $20 \mathrm{ml} / \mathrm{min}$ four solutions were used and contained increasing concentrations of glucose, namely, 66, 133, 200, and $260 \mathrm{mM} / \mathrm{l}$. These will be referred to respectively as solutions I, II, III, and IV. The concentration of sodium chloride concentration was $50 \mathrm{mM} / 1$ (except for solution IV where the concentration had to be reduced to $18 \mathrm{mM} / 1$ to maintain isoosmolarity). Mannitol was added to solutions I and II in concentrations of 125 and $60 \mathrm{mM} / \mathrm{l}$ respectively to produce isotonicity. However, the composition of so utions infused at $8 \mathrm{ml} / \mathrm{min}$ was slightly different: the glucose concentrations were $14,33,66,133$, and $260 \mathrm{mM} / \mathrm{l}$. The sodium chloride concentration was $60 \mathrm{mM} / 1$ (except in the last solution where it was $18 \mathrm{mM} / \mathrm{l})$. Mannitol was also added to reach isotonicity. The solutions all contained polyethylene glycol (PEG) in a concentration of $1 \mathrm{~g} / \mathrm{l}$, and they were adjusted to $p \mathrm{H} 7$. The exact number of subjects infused at each rate and at each concentration is indicated in Table III.
Perfusing solutions were warmed to $38^{\circ} \mathrm{C}$ and introduced by a constant rate infusion pump (Technicon). They were infused in each subject in a random order, and the effect of the balloon was studied by perfusing the same solution with the balloon inflated and then deflated or vice versa. Each solution was infused during an equilibration period of 45 minutes in order to obtain a steady state; jejunal samples were then collected by siphonage or gentle suction for three successive reriods of 10 minutes. The mean percentage discrepancy between triplicate PEG concentrations (ie, range expressed as percentage of the mean) did not exceed $10 \%$.

Glucose was estimated by reduction of potassium ferricyanide on a Technicon AutoAnalyzer. Sodium and potassium were measured by flame photometry and chloride by colorimetry on a Technicon AutoAnalyzer. Polyetheline glycol was determined in duplicate by the method of Hyden (1956) and osmolarity by freezing point depression on a Knauer osmometer.

The absorption rates were calculated as follows:

Water absorption $=\mathrm{V} \times\left(1-\frac{\mathbf{P E G}_{\mathbf{i}}}{\mathrm{PEG}_{\mathrm{D}}}\right)$

Solute absorption $=\mathrm{V} \times\left(\mathrm{Si}-\mathrm{S}_{\mathrm{D}} \frac{\mathrm{PEG}_{\mathrm{i}}}{\mathrm{PEG}_{\mathrm{D}}}\right)$

where $\mathrm{V}$ is the infusion rate, $\mathrm{Si}$ and $\mathrm{PEG}_{\mathrm{i}}$ are the infused concentrations of solute and PEG, and $S_{\mathbf{D}}$ and PEG $_{\mathrm{D}}$ are the solute and PEG concentrations in the distal samples.

\section{Results}

ESTIMATION OF REFLUX AND ENDOGENOUS SECRETIONS

Above the inflated balloon a volume of 0 to $300 \mathrm{ml}$ could be recovered within 70 minutes of infusion. The rate of recovery of these endogenous secretions revealed very large individual variations. In the same subject considerable changes within time were observed. Sometime the flow rate sampled above the balloon was spasmodic with sharp increases followed by total interruptions.

Above the deflated balloon fluid containing glucose and PEG was recovered in 14 out of 22 studies in which these substances were estimated. These concentrations of sugar and PEG were also highly variable; they were sometimes very low, compared to the infused solution, and sometimes comparable to the concentrations measured at the sampling site.

The comparison of absorption of glucose with inflated or deflated balloon disclosed highly signi- 


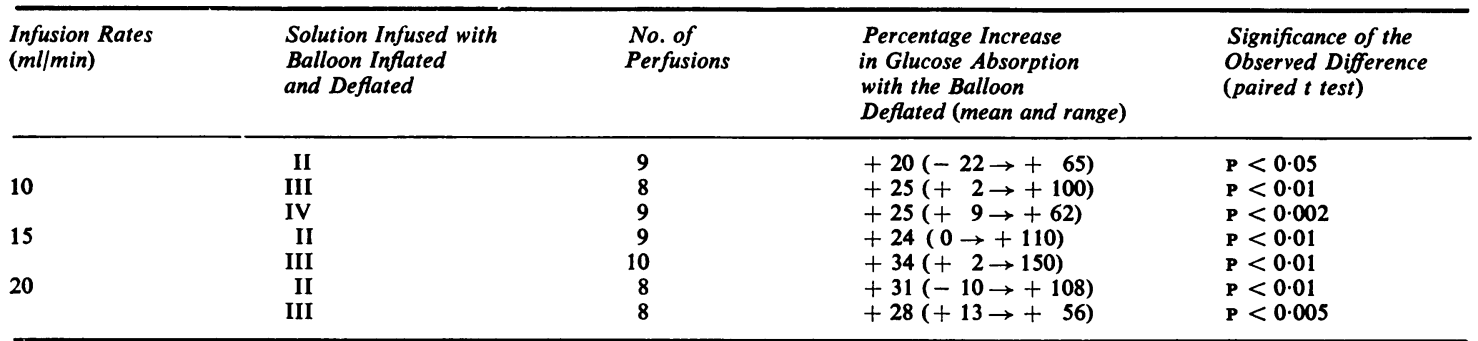

Table I Comparison of glucose absorption with the balloon deflated and inflated ${ }^{1}$

${ }^{2}$ Negative values indicate that glucose absorption was, in a few experiments, higher with the balloon inflated.

\begin{tabular}{|c|c|c|c|c|c|c|}
\hline \multirow[t]{2}{*}{ Solution } & \multicolumn{6}{|c|}{ Water Absorption $(\mathrm{ml} / \min / 25 \mathrm{~cm} ;$ mean $\pm S E)$} \\
\hline & \multicolumn{6}{|c|}{ Infusion Rate ( $\mathrm{ml} / \mathrm{min})$} \\
\hline II Balloon inflated & $1.43 \pm 0.45$ & $P>0.30$ & $0.84 \pm 0.93$ & $P<0.01$ & $0.96 \pm 0.76$ & $P<0.05$ \\
\hline $\begin{array}{l}\text { Balloon deflated } \\
\text { Balloon inflated }\end{array}$ & $\begin{array}{l}1.13 \pm 1.5 \\
0.73 \pm 0.54\end{array}$ & & $\begin{array}{l}1.54 \pm 0.62 \\
0.33 \pm 0.86\end{array}$ & & $\begin{array}{l}1.76 \pm 0.40 \\
0.33 \pm 1 \cdot 20\end{array}$ & \\
\hline 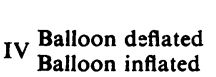 & $\begin{array}{l}1.57 \pm 1.57 \\
0.31 \pm 0.56\end{array}$ & $P>0.10$ & $1 \cdot 92 \pm 2 \cdot 15$ & $P<0.05$ & $1.40 \pm 0.97$ & $P<0.025$ \\
\hline Balloon deflated & $0.74 \pm 0.34$ & $P>0.45$ & Not done & & Not done & \\
\hline
\end{tabular}

Table II Comparison of water absorption from solutions II, III, and IV at three different infusion rates with the balloon inflated and deflated ${ }^{1}$

${ }^{1}$ At 15 and 20 minutes solution IV was only perfused with the balloon inflated.

ficant differences (Table I). The mean absorption rate was always higher when the balloon was deflated with a mean increase ranging from 20 to $34 \%$ of the absorption rate when the balloon was inflated; the difference was significant whatever the absorption rate and the solution infused. But, here again, individual variations were large (Table I). In some subjects perfusion with the balloon deflated resulted in an increase of more than double the glucose absorption rate, whereas in four out of 61 perfusions the absorption rate was slightly lower.

Absorption rate of water was significantly higher when the balloon was deflated for infusion rates of 15 and $20 \mathrm{ml} / \mathrm{min}$, but it was not significantly higher at $10 \mathrm{ml} / \mathrm{min}$ (Table II). No significant difference could be observed for sodium movements whether the balloon was inflated or deflated.

The validity of the steady state reached at the end of the equilibration period with the balloon inflated or deflated was compared. This was done by estimating the dispersion of PEG concentrations in the three consecutive 10-minute samples. For each solution infused the value and standard deviation of PEG concentrations were calculated for the three samples collected. The dispersion was expressed as the ratio of the standard deviation to the mean PEG value. These ratios obtained with the balloon inflated and deflated were compared by the paired $t$ test. Dispersion was found to be statistically higher with the balloon deflated when $10 \mathrm{ml} / \mathrm{min}$ or $15 \mathrm{ml} / \mathrm{min}$ were infused $(P<0.05)$, whereas it was not significantly different at an infusion rate of $20 \mathrm{ml} /$ minute.

All the results reported below concern only those perfusions performed with the balloon inflated.

EFFECTS OF VARYING FLOW RATES ON GLUCOSE ABSORPTION AND ITS KINETICS

This effect was tested at four different rates of infusion $(8,10,15$, and $20 \mathrm{ml} / \mathrm{min})$, with at least four different concentrations at each rate.

The results (Table III) indicate that, as a whole, the absorption rate is higher when the infusion rate of the same solution is increased. The difference observed between glucose absorption (for the same initial concentration) at increasing rates of flow can be seen from the data given in Table III. For an initial glucose concentration of $66 \mathrm{mM} / 1$ the difference on glucose absorption rate is significant between 10 and $15 \mathrm{ml} / \mathrm{min}(\mathrm{P}<0.01)$, and between 15 and $20 \mathrm{ml} / \mathrm{min}(P<0.05)$; for an initial concentration of $133 \mathrm{mM} / \mathrm{l}$ there is a significant difference for infusion rates between 8 and $20 \mathrm{ml} / \mathrm{min}$ $(P<0.025)$ and between 10 and $20 \mathrm{ml} / \mathrm{min}$ $(P<0.05)$; for an initial concentration of 200 


\begin{tabular}{|c|c|c|c|c|}
\hline \multirow{3}{*}{$\begin{array}{l}\text { Initial Glucose } \\
\text { Concentration } \\
(m M / l)\end{array}$} & \multicolumn{4}{|c|}{ Glucose Absorption Rate $(\mu M / \min / 25 \mathrm{~cm} ;$ mean $\pm S E)$} \\
\hline & \multicolumn{4}{|c|}{ Infusion Rates ( $\mathrm{ml} / \mathrm{min})$} \\
\hline & 8 & 10 & 15 & 20 \\
\hline $\begin{array}{r}14 \\
36 \\
66 \\
133 \\
200 \\
260\end{array}$ & $\begin{array}{l}109 \pm 5(6)^{1} \\
262 \pm 18(6) \\
472 \pm 60(6) \\
728 \pm 186(6) \\
\overline{820} \pm 263(3)\end{array}$ & $\begin{array}{l}- \\
- \\
459 \pm 46(10) \\
763 \pm 128(13) \\
841 \pm 188(12) \\
1,019 \pm 164(9)\end{array}$ & $\begin{array}{l}- \\
\overline{585} \pm 112(9) \\
885 \pm 262(9) \\
971 \pm 206(10) \\
999 \pm 257 \text { (9) }\end{array}$ & $\begin{aligned} &- \\
&-719 \pm 115(9) \\
& 913 \pm 162(8) \\
& 1,091 \pm 310(8) \\
& 1,042 \pm 261(9)\end{aligned}$ \\
\hline
\end{tabular}

Table III Glucose absorption under the inflated balloon at six different concentrations and four different infusion rates

${ }^{1}$ The figures in parentheses indicate the number of subjects in each group.

$\mathrm{mM} / \mathrm{l}$ the difference is significant between 10 and $20 \mathrm{ml} / \mathrm{min}(P<0.05)$; and no significant difference was found at a rate of $260 \mathrm{mM} / 1$. It can be noticed that (1) at the lowest concentration of sugar $(66 \mathrm{mM} / \mathrm{l})$ it is easy to demonstrate increasing absorption with increasing rates; (2) at the highest concentration $(260 \mathrm{mM} / \mathrm{l})$, whatever the rate, no significant difference can be shown; (3) for the intermediary concentrations (133 and $200 \mathrm{mM} / \mathrm{l})$ the difference is significant only between 8 or 10 $\mathrm{ml} / \mathrm{min}$ and $20 \mathrm{ml} / \mathrm{min}$.

If glucose absorption is not expressed as a rate, but as a percentage of infused load, it becomes evident that, at any concentration, the higher the rate, the lower this percentage.

The saturation phenomenon can be shown at each infusing rate by plotting the absorbed glucose against the arithmetic mean glucose concentration. Apparent maximum velocity (Vmax), and half saturation concentration $(\mathrm{Km})$ can be calculated by the method of Lineweaver and Burk, ie, by plotting of the reciprocal of the absorption rate against the reciprocal of the arithmetic mean glucose concentration for the different rates. The values for $\mathrm{Km}$ (expressed in $\mathrm{mM} / \mathrm{l}$ ) and for $\mathrm{Vmax}$ (expressed in $\mathrm{mM} / \mathrm{min} / 25 \mathrm{~cm}$.) are respectively 81.3 and 1.36 at an infused rate of $8 \mathrm{ml} / \mathrm{min} ; 99.7$ and 1.48 at a rate of $10 \mathrm{ml} / \mathrm{min} ; 43.0$ and 1.13 at $15 \mathrm{ml} / \mathrm{min}$; and 26.8 and 1.10 at $20 \mathrm{ml} / \mathrm{min}$. It is evident from these figures that the kinetic parameters are different according to the infusion rate, the most striking difference being for apparent $\mathrm{Km}$ values which dramatically decrease for an infusion rate above 10 $\mathrm{ml} / \mathrm{min}$. Therefore one must admit that the values for these parameters are dependent upon the experimental conditions, especially the infusion rate.

However, a different way of expressing the results can account, at least partially, for this unexpected finding. If the glucose absorption rate is plotted against the glucose infusion rate (instead of against the mean glucose concentration), a single curve can be drawn between the points of all experiments whatever the infusion rate (Fig. 2).

The validity of this assumption has been assessed by comparing for each separate infusion rate the regression lines of the Lineweaver and Burk plotting of the reciprocal of the absorbed glucose against the reciprocal of the glucose load. Covariance analysis was done on an IBM computer and showed that the regression lines were identical for 10,15 , and 20 $\mathrm{ml} / \mathrm{min}$ at a $5 \%$ level. It thus became possible, again using the Lineweaver regression line, to draw a general regression line between all individual results obtained at these three infusion rates. The equation of this line was:

$$
\frac{\mathrm{I}}{\mathrm{GA}}=0.870 \times \frac{\mathrm{I}}{\mathrm{GL}}+0.000757,
$$

where correlation coefficient $=0.834, \quad P<0.0005$, number of points $=112, \frac{\mathrm{I}}{\mathrm{GA}}=$ reciprocal of glucose absorption rate $(\mu \mathrm{M} / \mathrm{min} / 25)$, and $\frac{1}{\mathrm{GL}}=$ reciprocal of infused glucose load ( $\mu \mathrm{M} / \mathrm{min})$.

From this equation a common value for the kinetic parameters can be drawn, such that $\mathrm{Vmax}=1,320 \mu \mathrm{M} / \mathrm{min} / 25 \mathrm{~cm}$ and $\mathrm{Km}=1,150$ $\mu \mathrm{M} /$ minute.

This value of Vmax probably represents the actual maximum absorption rate of the test segment whatever the rate and the concentration of glucose infused. The value of $\mathrm{Km}$ can be interpreted as the half saturating glucose load. This single value for $\mathrm{Km}$ easily accounts for the apparent decrease of $\mathrm{Km}$ quoted above when mean glucose concentrations were used for calculation.

It must be noted that, although results obtained at $8 \mathrm{ml} / \mathrm{min}$ fit quite well with the single curve (Fig. 2), covariance analysis showed that, at this rate, the Lineweaver regression line was statistically different from the regression lines for infusion of 10 , 15 , and $20 \mathrm{ml} / \mathrm{min}$. 


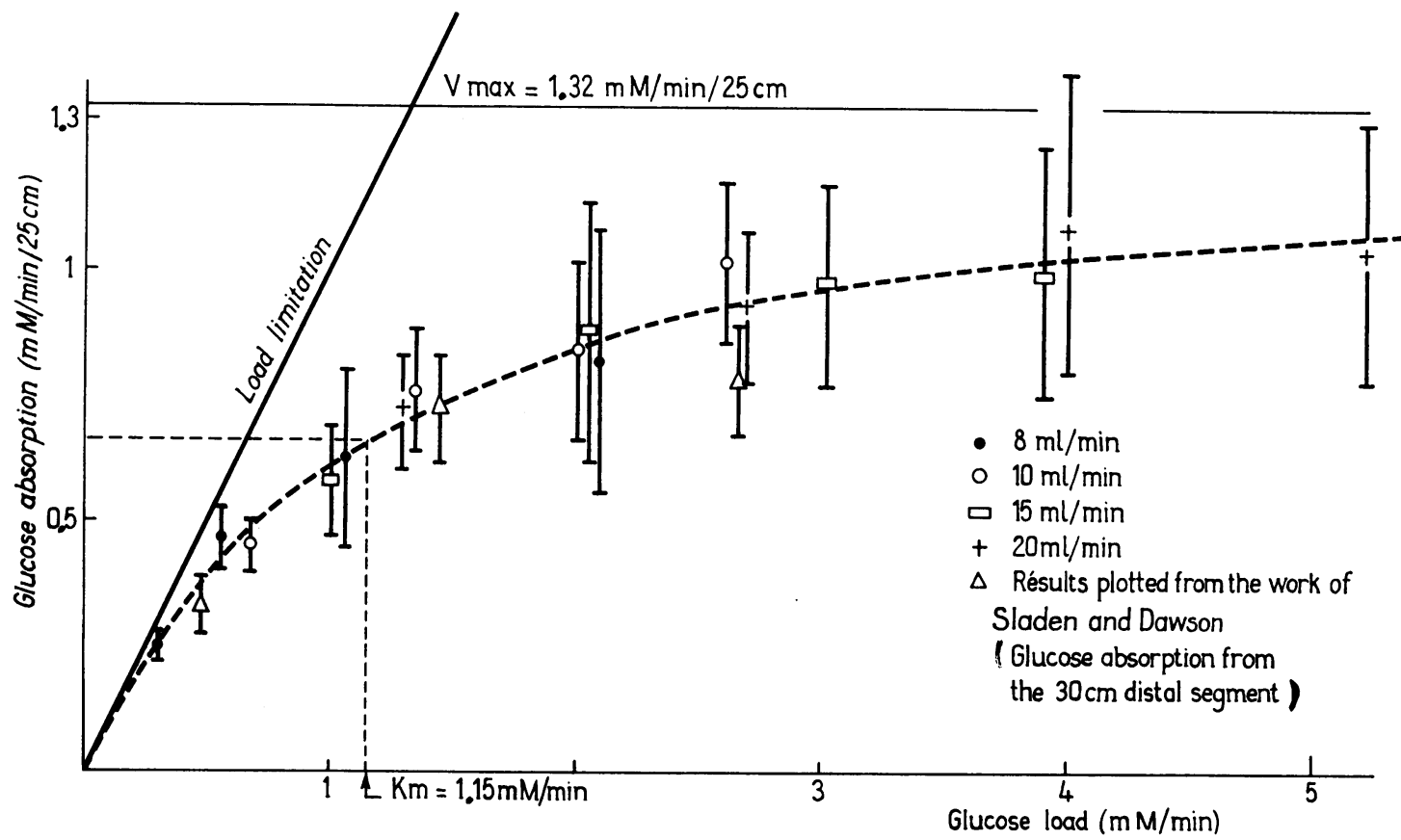

Fig. 2 Glucose absorption rates related to the glucose load. Note that the results obtained by Sladen and Dawson (1969b) in the distal $30 \mathrm{~cm}$ segment (for which the three-lumen method was used) fit quite well with the single curve proposed.

WATER AND SODIUM MOVEMENTS

The rates of water and sodium net movements are shown in Tables IV and V.

Effect of increasing glucose concentrations on water and sodium movements

It appears from Tables IV, V, and Vi that water absorption increases and sodium secretion decreases when the glucose concentration in the infused solution varies from $14 \mathrm{mM} / 1$ up to $133 \mathrm{mM} / 1$. This effect is more apparent at an infusion rate of $8 \mathrm{ml} / \mathrm{min}$ because four glucose concentrations below $200 \mathrm{mM} / 1$ have been tested. The same phenomenon is found when glucose concentrations of 66 and 133 $\mathrm{mM} / 1$ are infused at 10,15 or $20 \mathrm{ml} / \mathrm{min}$.

However, for an initially higher concentration of glucose $(200 \mathrm{mM} / \mathrm{l})$ even though the concentration of infused sodium remains unchanged, water absorption decreases and sodium secretion increases significantly. This general tendency of less water and sodium to be absorbed (or more to be secreted) is considerably more marked when the initial glucose concentration is $260 \mathrm{mM} / 1$ (but in this case initial sodium concentration is only $17 \mathrm{~m}$-equiv/l).

Effect of flow rate on ionic movements

Tables IV, V, and VI show that there is a general trend toward less water and sodium being absorbed (or more being secreted) when the infusion rate increases. The increase in sodium secretion is significant between 10 and $15 \mathrm{ml} / \mathrm{min}$ or 10 and 20 $\mathrm{ml} / \mathrm{min}$, or both, at any initial glucose concentration. The differences of water absorption for the same initial solution infused at 10,15 , or $20 \mathrm{ml} / \mathrm{min}$ are not significant, except for solution IV where water movements at $10 \mathrm{ml} / \mathrm{min}$ are significantly different from those observed at $15 \mathrm{ml} / \mathrm{min}(P<0.01)$ and $20 \mathrm{ml} / \mathrm{min}(\mathrm{P}<0.001)$. It is to be noted that these results cannot be validly compared with those measured at $8 \mathrm{ml} / \mathrm{min}$, since the initial sodium concentration was higher at this rate of infusion.

Table VII shows that the flux of potassium from blood to lumen (the infused solutions were free of potassium) increases significantly with increasing flow rate.

The correlation between sodium and water movements was always good, whatever the rate and the initial glucose concentration $(P<0.001)$. Isoosmotic absorption has always been maintained: osmolarity of the samples always fell between 275 and $305 \mathrm{mOsm} / \mathrm{l}$, and was not significantly different from the osmolarity of infused solutions. 


\begin{tabular}{|c|c|c|c|c|c|c|c|c|}
\hline \multirow{3}{*}{$\begin{array}{l}\text { Initial } \\
\text { Glucose } \\
\text { Concentration } \\
(m M / l)\end{array}$} & \multicolumn{8}{|c|}{ Water Absorption Rate (ml/min; mean $\pm S E)$} \\
\hline & \multicolumn{8}{|c|}{ Infusion Rate (ml/min) } \\
\hline & 8 & & 10 & & 15 & & 20 & \\
\hline 14 & $-1.34 \pm 0.49$ & $P<0.001$ & & & & & & \\
\hline 33 & $0.02 \pm 0.40$ & $P<0.001$ & & & & & & \\
\hline 66 & $1.02 \pm 0.30$ & $P<0.05$ & $0.22 \pm 0.40$ & $P<0.0005$ & $0.28 \pm 0.64$ & $P<0.025$ & $0.28 \pm 0.59$ & $P<0.01$ \\
\hline 133 & $1.95 \pm 1 \cdot 30$ & & $1.43 \pm 0.45$ & $P<0.0025$ & $0.84 \pm 0.93$ & $P<0.025$ & & $P>0.25$ \\
\hline $\begin{array}{l}200 \\
260\end{array}$ & $-0.30(-0.0$ & $\rightarrow-0.61)$ & $\begin{array}{l}0.73 \pm 0.54 \\
0.31 \pm 0.56\end{array}$ & & $\begin{array}{r}0.33 \pm 0.86 \\
-1.02 \pm 0.75\end{array}$ & & $\begin{array}{r}0.33 \pm 1.20 \\
-1.57 \pm 0.72\end{array}$ & \\
\hline
\end{tabular}

Table IV Comparison of water absorption rates from six different solutions infused at four different rates ${ }^{1}$ ${ }^{1}$ Negative values indicate net movement towards the lumen.

\begin{tabular}{|c|c|c|c|c|c|c|c|}
\hline \multirow{3}{*}{$\begin{array}{l}\text { Initial } \\
\text { Glucose } \\
\text { Concentration } \\
(m M / l)\end{array}$} & \multicolumn{7}{|c|}{ Sodium Movement ( $\mu$-equiv/min; mean $\pm S E$ ) } \\
\hline & \multicolumn{7}{|c|}{ Infusion Rate (ml/min) } \\
\hline & 8 & & 10 & & 15 & 20 & \\
\hline 14 & $-284 \pm 101$ & $P<0.001$ & & & & & \\
\hline 33 & $-194 \pm 95$ & $P<0.005$ & & & & & \\
\hline 66 & $-119 \pm 57$ & $P<0.05$ & $-186 \pm 45$ & $P<0.005$ & $-218 \pm 103$ ns & $-281 \pm 86$ & $P<0.005$ \\
\hline $\begin{array}{l}133 \\
200 \\
260\end{array}$ & $\begin{array}{l}-70 \pm 105 \\
-266(-187\end{array}$ & $-337)$ & $\begin{array}{l}-132 \pm 39 \\
-156 \pm 44 \\
-346 \pm 108\end{array}$ & $P<0.025$ & $\begin{array}{l}-213 \pm 88 \\
-243 \pm 116 \\
-460 \pm 146\end{array}$ & $\begin{array}{l}-183 \pm 91 \\
-257 \pm 112 \\
-543 \pm 145\end{array}$ & $P>0.05$ \\
\hline
\end{tabular}

Table V Comparison of sodium movements from six different solutions and at four different perfusion rates ${ }^{1}$

'Because of the low initial sodium concentrations this ion is always secreted into the lumen.

\begin{tabular}{|c|c|c|c|c|}
\hline \multirow{2}{*}{$\begin{array}{l}\text { Infusion } \\
\text { Rate } \\
\text { ( } \mathrm{ml} / \mathrm{min})\end{array}$} & \multicolumn{4}{|l|}{ Solution } \\
\hline & $I$ & II & III & IV \\
\hline $\begin{array}{l}10-15 \\
15-20 \\
10-20\end{array}$ & $\begin{array}{l}\text { ns } \\
\text { ns } \\
P<0.01\end{array}$ & $\begin{array}{l}P<0.01 \\
\text { ns } \\
P<0.05\end{array}$ & $\begin{array}{l}\mathrm{P}<0.05 \\
\text { ns } \\
\mathrm{P}<0.025\end{array}$ & $\begin{array}{l}\text { ns } \\
\text { ns } \\
P<0.025\end{array}$ \\
\hline
\end{tabular}

Table VI Significance of the differences observed between sodium secretions for the same initial solution infused at three different rates

\begin{tabular}{lll}
\hline Initial Flow Rate (ml/min) & Potassium Secretion ( $\mu$-equiv/min/25 cm) \\
\hline 10 & $36 \pm 5(39)^{1}$ & P $<0.001$ \\
15 & $45 \pm 9(40)$ & P $<0.05$ \\
20 & $50 \pm 10(35)$ & \\
\hline
\end{tabular}

Table VII Potassium secretion measured with three different flow rates

${ }^{1}$ Figures in parentheses indicate the number of perfusions for each rate.

\section{Discussion}

The use of a double- or a triple-lumen tube for intestinal perfusion has been extensively discussed in recent years. Studies on monosaccharides (Holdsworth and Dawson, 1964), disaccharides (Gray and Ingelfinger, 1966; Gray and Santiago, 1966; McMichael et al, 1967), and amino acids (Adibi, 1969) as well as investigation of the interrelationships between the absorption of sugars, water, and electrolytes (Sladen and Dawson, 1969a) have been performed with the double-lumen tube. It has been claimed that double- and triple-lumen methods provided similar results for the measurements of water and sodium absorption (Sladen and Dawson, 1968). However, the two-lumen tube has been severely criticized (Fordtran, 1969) because of two errors inherent in this method: contamination of the test segment by endogenous secretions and reflux of the infused solution proximal to the infusion point. This discussion culminated in an exchange of letters 
in Gut (Soergel, 1969). The use of a double-lumen tube with a proximal occluding balloon (which could be inflated or deflated) appeared to be a suitable method to investigate this problem. Our results undoubtedly outline the two errors of the doublelumen tube quoted above.

The contamination of the test segment by endogenous secretions was proved and quantitated by recovery above the inflated balloon of a volume varying between 0 and $300 \mathrm{ml}$ within 70 minutes, ie, 0 to $4.2 \mathrm{ml} / \mathrm{min}$. These results are in agreement with those reported by Phillips and Summerskill (1966) and by Whalen et al (1966) who, using a different method, showed that the flow rate of fasting intestinal contents into the segment studied was $2 \cdot 16 \pm 1 \cdot 32$ $\mathrm{ml} / \mathrm{min}$ in the jejunum. Besides the large individual variations of the flow rate of this contaminating fluid, our results reveal its important variability in the same subject, since sampling of this fluid above the inflated balloon was strikingly spasmodic. These variations easily explain why the steady state was not so good with the balloon deflated than inflated for infused rate of 10 and $15 \mathrm{ml} / \mathrm{min}$. It is likely that the contaminating effect is less troublesome when higher rates are infused, and that its variations affect the equilibration much less: this is what we found for an infusing rate of $20 \mathrm{ml} /$ minute.

The reflux of infused solution proximal to the infusion point was demonstrated by recovery 10 to $12 \mathrm{~cm}$ above this point of a fluid containing glucose and PEG. Fordtran (1969), by comparing absorption of tritiated water and ${ }^{14} \mathrm{C}$ urea with the double- and triple-lumen tube, found that fluid infused at 10 $\mathrm{ml} / \mathrm{min}$ spreads in a proximal direction for a distance of $20 \mathrm{~cm}$.

These two artifacts inherent in the double-lumen tube influenced in a different way absorption of glucose, water, and sodium. The reflux above the infusion point resulted in an unknown and presumably variable increase in length of the test segment which resulted in turn in an overestimation of glucose absorption. This overestimation could be as much as $150 \%$ of the measured value when the balloon was inflated with the mean ranging between 20 and $34 \%$ according to the solution and the rate infused. This probably explains why we found glucose absorption much lower than other workers who used a double-lumen tube. Holdsworth and Dawson (1964) infusing at a rate of $20 \mathrm{ml} / \mathrm{min}$ a solution containing $25 \mathrm{~g} / 1$ of glucose measured an absorption rate of about $53 \mu \mathrm{mol} / \mathrm{min} / \mathrm{cm}$ and calculate a value of $V \max$ of $135 \mu \mathrm{mol} / \mathrm{min} / \mathrm{cm}$. At the same infused rate and with a solution containing $24 \mathrm{~g} / \mathrm{l}$ of glucose we measured an absorption rate of $36 \mu \mathrm{m} / \mathrm{min} / \mathrm{cm}$ and a $V \max$ of $44 \mu \mathrm{m} / \mathrm{min} / \mathrm{cm}$. Under identical experimental conditions, but with the balloon deflated, we found an absorption rate of $48 \mu \mathrm{m} / \mathrm{min} / \mathrm{cm}$. On the other hand, it is evident that the pollution phenomenon does not influence glucose absorption, since fasting intestinal fluid contains negligible amounts of glucose.

When the balloon was inflated water absorption was found to be higher at infusion rates of 15 and $20 \mathrm{ml} / \mathrm{min}$. This result is at variance with the opinion generally held that the double-lumen method underestimates the absorption of water (Whalen et al, 1966; Fordtran, 1969). Our results probably mean that under our experimental conditions the proximal reflux prevailed over the effect of the pollution phenomenon.

Sodium absorption is also said to be underestimated by the double-lumen tube. However we could not find any statistical difference whether the balloon was inflated or deflated. This result is rather difficult to account for, since, with the low concentration of sodium we infused, both reflux and contamination should have resulted in an increased sodium secretion when the balloon was deflated. The large individual variations observed in sodium movement may account for this result.

It is necessary to discuss a possible inhibitory effect of the balloon itself on the absorption mechanism. Phillips and Summerskill (1966) have demonstrated that, during inflation, the motility of the gut was reduced. Studies on correlation between intestinal absorption and motility did not demonstrate any inhibitory effect of hypomotility on sugar absorption. Cummins and Almy (1953) failed to alter, by using banthine, the glucose tolerance test when glucose was introduced in the duodenum, and Fordtran, Soergel, and Ingelfinger (1962) found that atropinization increased the intestinal absorption of xylose. Groissier and Farrar (1960) conclude that hypomotility probably does not play a critical role in the absorption of isotopic sodium in the normal small intestine, although Higgins, Code, and Orvis (1956) found rather opposite results. Moreover studies on water and ions absorption done with the proximal occluding balloon (Phillips and Summerskill, 1967) and with the triple-lumen tube (Rambaud, personal communication) provided similar results. Thus an inhibitory effect of the inflated balloon on the absorption of sugars, water, and sodium seems unlikely, although not impossible. Finally, it can be concluded from our results with the balloon inflated and deflated that (1) both pollution and reflux do occur with the balloon deflated, and (2) under our experimental conditions absorption rates were more affected by the reflux than by the pollution.

Our results confirm that glucose absorption is a saturable phenomenon. This fact has already been found in vitro and in vivo by intestinal perfusions in 
man (Schedl and Clifton, 1961; Holdsworth and Dawson, 1964) and has been interpreted as evidence for a carrier transport system for glucose. Increasing the flow rate increases glucose absorption rate. This effect is more important when infused glucose concentration is low, ie, when a load-limited situation is approached. But, this effect is still present for higher glucose concentrations, whereas load limitation can no longer be invoked, as shown in Table III and Figure 2. For the highest glucose concentration, the increase in glucose load does not affect absorption rate of this sugar, presumably because saturation of the segment is approached, as will be discussed below.

There is a decrease in values of apparent $\mathrm{Km}$ for high infusion rates when 'traditional' Lineweaver and Burke plotting is used (ie, when the reciprocal of glucose concentration is plotted on abscissae). This result would theoretically mean that as the infusion rate increases, the apparent affinity of the carrier for glucose would be higher. Such an interpretation is rather difficult to accept. The difference in concentration along the segment does not seem to explain the variation of apparent $\mathrm{Km}$ with the rate of infusion. Sladen and Dawson (1969b) predict that glucose absorption would be better correlated with the initial glucose concentration (Gi) when the fractional fall in concentration ( $f=$ drop in concentration down segment/Gi) is low (ie, less than $60-70 \%$. In our experiments $f$ was almost always less than $70 \%$. Therefore the factor

$\mathrm{F}\left(\mathrm{f}=\frac{1}{\mathrm{f}} \log _{\mathrm{e}} \frac{1}{1-\mathrm{f}}\right)$ which takes the concentration

profile into account varies little with the rate of infusion and the initial glucose concentration. Consequently, an attempt to introduce this factor $F$ in our calculation (by plotting the reciprocal of the glucose absorption rate against $\mathrm{F} / \mathrm{Gi}$ ) did not give a single value of $\mathrm{Km}$ for the four rates of infusion. However, if glucose absorption rate is plotted against glucose load, as initially proposed by Holdsworth and Dawson (1964), the discrepancy between the infusion rates disappears, a common curve can be drawn, and single values of $\mathrm{Km}$ and Vmax can be calculated. Thus it can be presumed that this value for $V \max (1.320 \mathrm{mM} / \mathrm{min} / 25 \mathrm{~cm}$ or $53 \mu \mathrm{M} / \mathrm{min} / \mathrm{cm}$ ) represents the actual maximum absorption capacity of the segment, and that it is almost reached for a load of $3 \mathrm{mM} / \mathrm{min}$. However, Holdsworth and Dawson (1964) found a much higher theoretical value for $\operatorname{Vmax}(135 \mu \mathrm{M} / \mathrm{min} / \mathrm{cm})$ and could also measure higher absorption rates (about $70 \mu \mathrm{M} / \mathrm{min} / \mathrm{cm}$ ) for an infused glucose concentration of $50 \mathrm{~g} / 1$. This discrepancy is probably explained by the reflux of infused solution as discussed above. Figure 2 shows that half the saturating load for a $25 \mathrm{~cm}$ long segment of jejunum is of $1.15 \mathrm{mM} / \mathrm{min}$. This value cannot be properly called apparent $\mathrm{Km}$ since it does not represent a concentration but a load. It accounts easily for the effect of the rate on 'traditional' $\mathrm{Km}$ : the higher the rate, the lower the concentration which will give half-saturation.

This method of interpreting glucose absorption kinetics can be applied to the results published by Sladen and Dawson (1969b) concerning the effects of flow rate on glucose transport. These workers found for a theoretical segment $15 \mathrm{~cm}$ long an absorption rate of about $1.05 \mathrm{mM} / \mathrm{min} / 15 \mathrm{~cm}$ and this figure was not influenced by more than a twofold increase of the infusion rate. The authors interpret this result as a maximum absorption rate for a given initial concentration, and not as a saturation of the absorption capacity itself. In fact, it seems likely that this absorption rate does indeed represent the actual saturation of the segment $15 \mathrm{~cm}$ long, and presumably of a longer segment: if one assumes that Vmax is proportional to the segment length, the theoretical maximal velocity should be of about $0.8 \mathrm{mM} / \mathrm{min} / 15 \mathrm{~cm}$. The results published are higher presumably because of reflux above the infusion point. However, the reflux artifact cannot be invoked for the distal $30 \mathrm{~cm}$ long segment, since the absorption was measured in this case with a triple-lumen method, and under these experimental conditions absorption rates measured at three different infusion rates fit quite well with the single curve we proposed, as shown in Figure 2.

Glucose does stimulate sodium and water absorption as shown on Tables IV and V. Under our experimental conditions, this phenomenon resulted in an increase in water absorption and a decrease in sodium secretion. Although unidirectional fluxes of sodium were not measured in our study, it seems logical to assume a priori that glucose stimulates the lumen-to-blood movement of sodium. Schultz and Zalusky (1964), who employed a short-circuited preparation of rabbit ileum, showed that the increase in the short circuit current induced by the addition of glucose to the solution perfusing the mucosal side of the preparation could be entirely attributed to an increase in the rate of active sodium transport from mucosa to serosa. Summers and Schedl (1968) found also that intraluminal glucose increased net absorption and lumen-to-blood movement of sodium on perfused small intestine of rats in vivo. However, Nelson and Beargie (1965) found in the dog jejunum that glucose absorption was correlated with the movement of sodium from blood to lumen and not with the reverse movement. Nevertheless, 
their experimental conditions may have modified the function of the intestine.

This stimulatory effect of glucose on water and sodium movement was found to increase gradually with solutions containing 14 to $133 \mathrm{mM} / \mathrm{l}$ of sugar. However, Schultz and Zalusky (1964) found on rabbit ileum, a saturation of the stimulating effect on sodium transport for glucose concentration of $20 \mathrm{mM} / 1$. Analogous results were reported by Malawer, Ewton, Fordtran, and Ingelfinger (1965) and recently by Sladen and Dawson (1969a) by intestinal perfusion in man: these authors found that the effect of glucose on water transport was gradual but reached a maximum for an initial glucose concentration of $56 \mathrm{mM} / 1$ and that the effect of the sugar on sodium absorption was of the 'all-ornothing' type, the maximum effect being observed for an initial glucose concentration of $14 \mathrm{mM} / \mathrm{l}$. This discrepancy might well be explained by the experimental conditions. Sladen and Dawson (1969a) used higher and variable initial sodium concentrations (inversely related to initial glucose concentrations) whereas we used lower and constant initial sodium concentrations. In this connexion it can be noticed that Fordtran et al (1968), in a series of experiments where sodium concentration was kept constant in the segment studied, found that the stimulating effect of glucose or sodium absorption increased when concentration of the sugar infused varied from 0 to $105 \mathrm{mM} / 1$ (while the mean glucose concentration in the test segment ranged between 0 and about $40 \mathrm{mM} / \mathrm{l})$. It remains that the mechanism of the effect of glucose on sodium and water movement cannot be soundly discussed from our data, and it is not possible to determine whether the sugar exerts its primary effect on sodium or on water.

For an initial glucose concentration of $200 \mathrm{mM} / 1$, sodium secretion increases and water absorption desreases although the initial sodium concentration was kept constant. An analogous effect was reported by Holdsworth and Dawson (1964) when they compared absorption of water from solutions containing 140 and $280 \mathrm{mM} / 1$ of glucose. In this work, however, sodium concentration was not kept constant, since isoosmolarity was adjusted by $\mathrm{NaCl}$. More convincing evidence of this phenomenon was then reported by McMichael et al (1967), who also observed a drop in water absorption with $5 \%$ maltose solution, containing $80 \mathrm{~m}$-equiv/l $\mathrm{Na}$, which gave the same absorption of glucose as a $5 \%$ glucose solution.

Our results with constant sodium concentrations confirm that above a given level of intraluminal glucose concentration both water and sodium absorption drop. This effect seems actually to be correlated with the glucose concentration and not with the glucose absorption rate, whereas at a rate of $10 \mathrm{ml} / \mathrm{min}$ this phenomenon appears when glucose absorption rate increases from $763 \mu \mathrm{M} / \mathrm{min} / 25$ $\mathrm{cm}$ (for an initial glucose concentration of $133 \mathrm{mM} / \mathrm{l}$ ) to $841 \mu \mathrm{M} / \mathrm{min} / 25 \mathrm{~cm}$ (for an initial glucose concentration of $200 \mathrm{mM} / \mathrm{l}$ ); it does not appear when, at $20 \mathrm{ml} / \mathrm{min}$, sugar absorption rates vary from 719 $\mu \mathrm{M} / \mathrm{min} / 25 \mathrm{~cm}$ (for an initial glucose concentration of $66 \mathrm{mM} / \mathrm{l}$ ) to $913 \mu \mathrm{M} / \mathrm{min} / 25 \mathrm{~cm}$ (for an initial glucose concentration of $133 \mathrm{mM} / \mathrm{l})$. At the latter rate, the drop in water and sodium absorption occurs only when initial glucose concentration reaches 200 $\mathrm{mM} / \mathrm{l}$. The mechanism of this phenomenon is by no means clear. Saturation of the stimulatory effect of glucose on water and sodium movements cannot be invoked, since, in this hypothesis, these movements should remain constant and not decrease. This phenomenon is much more important with an initial glucose concentration of $260 \mathrm{mM} / 1$ presumably because of the low initial sodium level.

High flow rates result in a decrease in water absorption rate and increase in sodium secretion. This phenomenon may be interpreted as an increase in the movement of water and sodium from blood to lumen. This hypothesis is suggested by the significantly higher secretion of potassium from blood to lumen as shown in Table VII (the infused solution was free of potassium). The mechanism of this supposed increase in hydroionic movement from blood to lumen remains unexplained.

The authors wish to thank Mrs C. Thiry, A. Evrard, and A. Lebert for their technical assistance. We are also indebted to Mr Mary for his useful cooperation in the statistical part of this work. One of us (R.M.) was assisted by a grant from the Medical Society of the Paris hospitals.

\section{References}

Adibi, S. A. (1969). The influence of molecular structure of neutral amino acids on their absorption kinetics in the jejunum and ileum of human intestine in vivo. Gastroenterology, 56, 903-913.

Cummins, A. J., and Almy, T. P. (1953). Studies on the relationship between motility and absorption in the human small intestine. Gastroenterology, 23, 179-190.

Fordtran, J. S. (1969). Segmental perfusion techniques (Comment). Gastroenterology, 56, 987-989.

Fordtran, J. S., Rector, F. C. Jr., and Carter, N. W. (1968). The mechanisms of sodium absorption in the human small intestine. J. clin. Invest., 47, 884-900.

Fordtran, J. S., Soergel, K. H., and Ingelfinger, F. J. (1962). Intestinal absorption of D-xylose in man. New Engl. J. Med., 267, 274-279.

Gray, G. M., and Ingelfinger, F. J. (1966). Intestinal absorption of sucrose in man-interrelation of hydrolysis and monosaccharide product absorption. J. clin. Invest., 45, 388-398. 
Gray, G. M., and Santiago, N. A. (1966). Disaccharide absorption in normal and diseased human intestine. Gastroenterology, 51, 489-498.

Groissier, V. W., and Farrar, J. T. (1960). Absorption of radioactive sodium from the intestinal tract of man. I. Effect of intestinal motility. II. Effect of an organomercurial. J. clin. Invest., 39, 1607-1618.

Higgins, J. A., Code, C. F., and Orvis, A. L. (1956). The influence of motility on the rate of absorption of sodium and water from the small intestine of healthy persons. Gastroenterology, 31, 708-716.

Holdsworth, C. D., and Dawson, A. M. (1964). The absorption of monosaccharides in man. Clin. Sci., 27, 371-379.

Hyden, S. (1956). A turbidometric method for the determination of higher polyethylene glycols in biological materials. $K$. LantbrHögsk. Annlr., 22, 139-145.

McMichael, H. B., Webb, J., and Dawson, A. M. (1967). The absorption of maltose and lactose in man. Clin. Sci., 33, 135-145.

Malawer, S. J., Ewton, M., Fordtran, J. S., and Ingelfinger, F. J. (1965). Interrelation between jejunal absorption of sodium, glucose, and water in man. (Abstr.) J. clin. Invest., 44, 1072.

Nelson, R. A., and Beargie, R. J. (1965). Relationship between sodium and glucose transport in canine jejunum. Amer. $J$. Physiol., 208, 375-379.

Phillips, S. F., and Summerskill, W. H. J. (1966). Occlusion of the jejunum for intestinal perfusion in man. Mayo Clin. Proc., 41, 224-231.

Phillips, S. F., and Summerskill, W. H. J. (1967). Water and electro- lyte transport during maintenance of isotonicity in human jejunum and ileum. J. Lab. clin. Med., 70, 686-698.

Schedl, H. P., and Clifton, J. A. (1961). Kinetics of intestinal absorption in man: normal subjects and patients with sprue. (Abstr.) J. clin. Invest., 40, 1079-1080.

Schultz, S. G., and Zalusky, R. (1964). Ion transport in isolated rabbit ileum: II-The interaction between active sodium and active sugar transport. J. gen. Physiol., 47, 1043-1059.

Sladen, G. E., and Dawson, A. M. (1968). An evaluation of perfusion techniques in the study of water and electrolyte absorption in man: the problem of endogenous secretions. Gut, 9, 530-535.

Sladen, G. E., and Dawson, A. M. (1969a). Interrelationships between the absorption of glucose, sodium and water by the normal human jejunum. Clin. Sci., 36, 119-132.

Sladen, G. E., and Dawson, A. M. (1969b). Effects of flow rate on the absorption of glucose in a steady state perfusion system in man. Clin. Sci., 36, 133-146.

Soergel, K. H. (1969). An evaluation of perfusion techniques in the study of water and electrolyte absorption in man. (Comment, with reply by G. E. Sladen and A. M. Dawson.) Gut, 10, 601602.

Summers, R. W., and Schedl, A. P. (1968). Effects of tonicity and glucose on intestinal sodium and water absorption in the rat. Scand. J. Gastroent., 3, 376-382.

Whalen, G. E., Harris, J. A., Grenen, J. E., and Soergel, K. H. (1966). Sodium and water absorption from the human small intestine. The accuracy of the perfusion method. Gastroenterology, 51, 975-984.

\section{The February 1971 Issue}

\section{THE FEBRUARY 1971 ISSUE CONTAINS THE FOLLOWING PAPERS}

Effect of cigarette smoking on human gastric secretory responses H. T. DEBAS, M. M. COHEN, I. B. HOLUBITSKY, AND R. C. HARRISON

Radioimmunoassay of gastrin: studies in pernicious anaemia J. HANSKY, M. G. KORMAN, C. SOVENY, AND D. J. B. ST JOHN

Pyloric incompetence in chronic non-specific lung disease MICHAEL BEELEY AND PAUL GRECH

Disaccharidase levels in the small intestine in patients with diarrhoea following vagotomy and pyloroplasty J. GARCIA-PAREDES AND S. C. TRUELOVE

The value of electron microscopestudies in diagnosing malignant change in ulcerative colitis JANET A. JENKINSON AND I. M. P. DAWSON

Trends in mortality from ulcerative colitis in England and Wales J. GRIMLEY EVANS

The effect of nitrogen mustard intoxication on glucose absorption from the small intestine of the rat M. J. LEIBOWITZ AND P. C. MERKER
Intestinal spirochaetosis F. D. LEE, A. KRASZEWSKI, J. GORDON, J. G. R. HOWIE, D. MCSEVENEY, AND W. A. HARLAND

Stimulation of insulin secretion by medium-chain triglycerides in patients with cirrhosis FRANK $\mathbf{S}$. MCCULLOUGH, MANUEL TZAGOURNIS, NORTON J. GREENBERGER, AND WILLEM G. LINSCHEER

Copper kinetics in liver disease R. A. SMALLWOOD, B. MCILVEEN, V. M. ROSENOER, AND S. SHERLOCK

Serum bile acids in liver disease G. NEALE, B. LEWIS, V. WEAVER, AND D. PANVELIWALLA

Renal tubular acidosis and autoimmune liver disease PETER L. GOLDING AND ALISTAIR S. M. MASON

The effect of metoclopramide on gastroduodenal and gallbladder contractions A. G. JOHNSON

Carrageenan-induced ulceration of the large intestine in the guinea pig J. WATT AND R. MARCUS

Progress report Thyroid hormones and the gut W. R. J. MIDDLETON

Notes and activities

Copies are still available and may be obtained from the PUBLISHING MANAGER BRITISH MEDICAL ASSOCIATION, TAVISTOCK SQUARE, LONDON, WC1H 9JR, price $87 \frac{1}{2} \mathrm{p}$. 